\title{
Is a Femoro-Acetabular Impingement Type Cam Predictable after Slipped Capital Femoral Epiphysis?
}

\author{
Nils Wirries ${ }^{1}{ }^{\circledR}$, Gesche Heinrich ${ }^{1}$, Alexander Derksen ${ }^{1}$, Stefan Budde ${ }^{1}{ }^{\circ}$, Thilo Floerkemeier ${ }^{2}$ \\ and Henning Windhagen ${ }^{1, *}$ \\ 1 Department of Orthopaedic Surgery at Diakovere Annastift, Hannover Medical School, 30625 Hannover, Germany; \\ Nils.Wirries@diakovere.de (N.W.); Gesche.M.Heinrich@stud.mh-hannover.de (G.H.); \\ Alexander.Derksen@diakovere.de (A.D.); st-budde@t-online.de (S.B.) \\ 2 go:h Gelenkchirurgie-Orthopädie: Hannover, 30159 Hannover, Germany; thilo.floerkemeier@g-o-hannover.de \\ * Correspondence: henning.windhagen@diakovere.de; Tel.: +49-511-5354-0; Fax: +49-511-5354-682
}

Citation: Wirries, N.; Heinrich, G.; Derksen, A.; Budde, S.; Floerkemeier, T.; Windhagen, $\mathrm{H}$. Is a

Femoro-Acetabular Impingement Type Cam Predictable after Slipped Capital Femoral Epiphysis? Children 2021, 8, 992. https://doi.org/

$10.3390 /$ children 8110992

Academic Editor: Reinald Brunner

Received: 26 September 2021

Accepted: 27 October 2021

Published: 2 November 2021

Publisher's Note: MDPI stays neutral with regard to jurisdictional claims in published maps and institutional affiliations.

Copyright: (c) 2021 by the authors. Licensee MDPI, Basel, Switzerland. This article is an open access article distributed under the terms and conditions of the Creative Commons Attribution (CC BY) license (https:// creativecommons.org/licenses/by/ $4.0 /)$.

\begin{abstract}
Background: Previous studies have proven a high incidence of a femoro-acetabular impingement (FAI) type cam in patients sustaining a slipped capital femoral epiphysis (SCFE). Thus, the current study analyzed, if a cam deformity is predictable after SCFE treatment; (2) Methods: 113 cases of SCFE were treated between 1 January 2005 and 31 December 2017. The radiological assessment included the slip angle after surgery (referenced to the femoral neck (epiphyseal tilt) and shaft axis as Southwick angle) and the last available lateral center edge angle (LCEA), the acetabularand alpha angle. A correlation was performed between these parameters and the last alpha angle to predict a FAI type cam; (3) Results: After a mean follow-up of 4.3 years $( \pm 1.9 ; 2.0-11.2), 48.5 \%$ of the patients showed a FAI type cam and $43.2 \%$ a dysplasia on the affected side. The correlation between the epiphyseal tilt and alpha angle was statically significant $(p=0.017)$ with a medium effect size of 0.28; (4) Conclusions: The postoperative posterior epiphyseal tilt was predictive factor to determine the alpha angle. However, the cut-off value of the slip angle was $16.8^{\circ}$ for a later occurrence of a FAI type cam indicating a small range of acceptable deviations from the anatomical position for SCFE reconstruction.
\end{abstract}

Keywords: slipped capital femoral epiphysis; femoro-acetabular impingement; prognostic factor; correlation

\section{Introduction}

The slipped capital femoral epiphysis (SCFE) is a hip disorder in the immature skeleton with an incidence between 0.33-24.85/100,000 [1]. In most cases the capital femoral epiphysis slides from the metaphysis in a medial-posterior direction (varus), but lateral-posterior displacements (valgus) are also described [2]. While an atypical type is caused by a known trigger including endocrine disorders, renal osteodystrophy or radiation treatment, the majority is idiopathic and only associated with general risk factors, especially obesity [3,4]. The affected children are on average between 11.7-13.0 years of age in dependence of the gender, causing females to usually sustain earlier a SCFE [5]. The disease occurs bilaterally in up to $80.0 \%$, therefore the unaffected side can be treated in a prophylactic attempt [6]. The surgical procedures for the SCFE range from a closed reduction and internal fixation with wires or screws to open treatment options with osteotomies [7]. Independent of the chosen procedure, the overall aim is to restore and stabilize the anatomical position of the capital femoral epiphysis as close to natural as possible to achieve a physiological femoral neck junction and reduce the risk for osteonecrosis of the femoral head. A remaining incongruence and a remodeling process after the slip and the following treatment may cause a femoro-acetabular impingement (FAI) type cam in the early adolescence. The FAI was firstly described by Ganz et al. and represents a bony conflict between the acetabular rim and the femoral head-neck junction [8]. Generally, three types were differentiated. The FAI type pincer is defined as a local or general overcoverage of the femoral head due to 
prominence of the acetabular rim (for example in case of a retroversion, coxa profunda). The femoral deformity, the most common type, is described as FAI type cam and represents a bone thickening at the femoral head-neck junction leading to a mechanical conflict. The third type is a mixed type combining an acetabular and femoral deformity [9]. On the one hand the severity of the displacement (moderate, mild, severe) correlates with the rate of a FAI development, on the other hand a post-slip remodeling might influence the remaining femoral neck deformity $[10,11]$. According to this, the rate of the occurrence of a post-slip FAI was less common in patients younger than 11 years and might be explained by an extended time period of remodeling potential [12]. The FAI type cam is defined with an elevated alpha angle $>55.0^{\circ}$ (physiological range $<55.0^{\circ}$ ), which represents an angle between the femoral neck axis and a line connecting the center of the femoral head and the point of the bony head contour with a greater distance to the center than the radius [13]. Overall, the rate of FAI associated hip osteoarthritis was described with up to $91.0 \%$ in SCFE patients, compared to $43.0 \%$ in non-SCFE patients [10]. Fraitzl et al. reviewed 16 mild SCFE patients and observed a rate of elevated values of the alpha angle in all cases ranging from 55 to $99^{\circ}$ [14]. The local bony thickening at the femoral neck leads to groin pain by damaging the acetabular labrum and the cartilage [15-17]. If left untreated, a FAI type cam might be responsible for an early onset osteoarthritis of the hip [18]. With a reshaping procedure of the femoral neck junction in an arthroscopic, arthroscopically-assisted or open setting, the progression of the joint degeneration may be prolongated and the total hip arthroplasty (THA) - free life time enhanced [19]. Hence, it is important to know which patients with a SCFE in their history are predestinated to develop a FAI type cam. With this information, the care of high-risk patients can be scheduled regularly over years to detect a symptomatic bony bump in an early stage. Further, in previous literature also an association between a SCFE and the development of a dysplastic socket shape and otherwise severe slips and a coxa profunda was observed [20,21].

Thus, the first aim was to detect the prevalence of pathological hip anatomies after SCFE (1). Another aim of this study was to analyze predictive factors in patients with a SCFE that may cause development of a FAI type cam over time (2).

\section{Materials and Methods}

This retrospective study was approved by the local ethic committee (No. 8779, Hanover Medical School, 28 November 2019). The inclusion criterium was a surgical treatment of a SCFE between 1 January 2005-31 December 2017 in our clinic (Department of Orthopaedic Surgery at Diakovere Annastift, Hannover Medical School) and included 113 cases in 111 patients. Exclusion criteria were missing radiological follow-up examination (e.g., due to outside follow-up examinations) or disapproval for participation. According to this, 18 cases (15.9\%) resp. 15 patients (3 patients with a bilateral SCFE, 12 patients with a unilateral SCFE) were excluded from the study due to missing follow-up radiographs (at least two years) for the analysis of FAI type cam predicting factors. All patients were treated either with wires or with screws. The diagnosis was made with a radiological examination in two planes, pelvic anterior-posterior (a.p., standardized in supine position) and lateral views on both sides. All patients received postoperative physiotherapy training, including unloading or partial weight bearing for 6 weeks, depending on the patient's age, weight and compliance.

The radiological analysis directly after surgical fixation included the lateral center edge angle according to the sourcil method (LCEA) [22] and the acetabular angle (inclination) to evaluate the femoral coverage [23], especially regarding the presence of a hip dysplasia or coxa profunda, as well as the absolute slip angle according to Southwick $[24,25]$. The grading of the Southwick angle values is typically: mild $\left(<30^{\circ}\right)$, moderate $\left(30-50^{\circ}\right)$ and severe $\left(>50^{\circ}\right)$. Because the alpha angle is referenced to the femoral neck axis, this reference was the same for the posterior epiphyseal tilt to predict a FAI type cam over the time [26]. In contrast to the Southwick angle, which is determined as an angle between the slipped capital epiphysis and the femoral shaft axis, the posterior epiphyseal tilt was referenced 
also to the femoral neck axis like the alpha angle [27]. In addition, parameters for dysplasia resp. retroversion were evaluated, including the crossover sign (the anterior and posterior acetabular rims crossing on the pelvic a.p.) and the prominence of the ischial spine (PRISS; the ischial spine is projected in the lesser pelvic on the pelvic a.p.) [28]. In presence of a crossover sign and a positive PRISS a retroversion was assumed, whereas a dysplasia was defined with a LCEA $<20$ and an inclination $>10^{\circ}$. All the described values were assessed again at the last time of the radiological follow-up, additionally the alpha angle [13]. In presence of a SCFE, the center of the femoral head is not always aligned to the axis of the femoral neck for measurement of the alpha angle and the posterior epiphyseal tilt. To avoid inaccuracy, the anatomical method according to Bouma et al. was used [29]. For this, the femoral neck axis was defined with three circles along the femoral neck, whichever fitted the bony neck best (Figures 1 and 2).

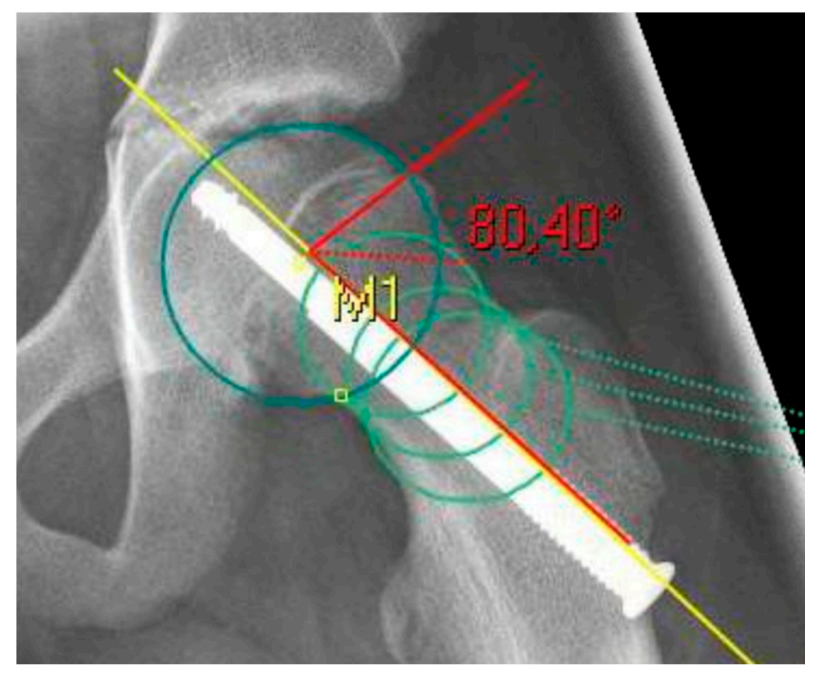

Figure 1. X-ray after screw fixation of a left sided SCFE as an example for the measurement of the alpha angle. The femoral neck axis (yellow line) was determined with three circles (light green) according to Bouma [29].

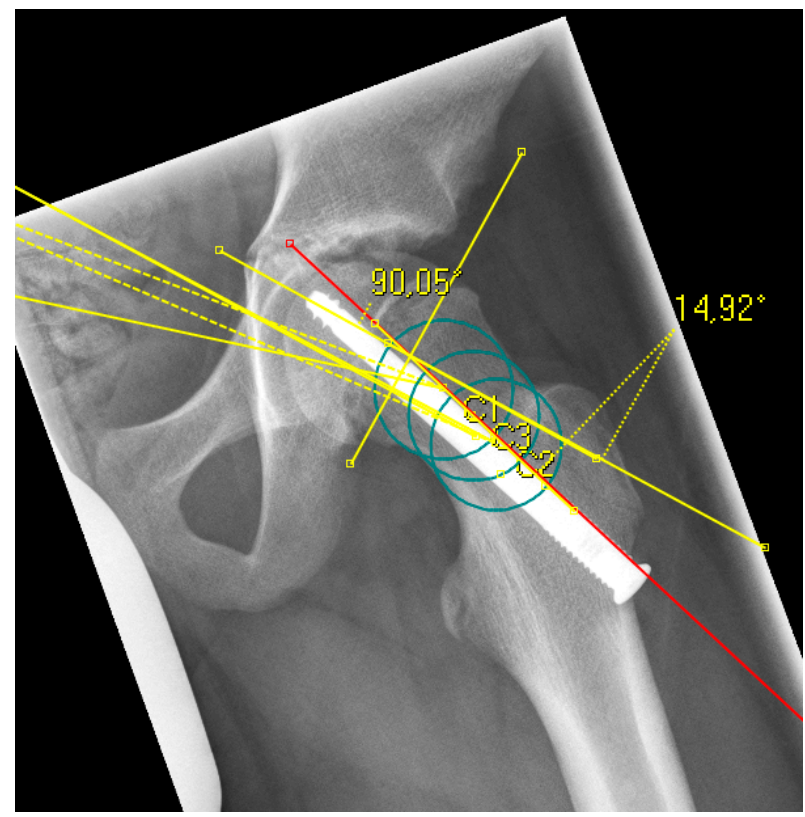

Figure 2. Example of a radiograph with the measurement of the epiphyseal tilt based on the anatomical femoral neck axis (red line), which was determined with three circles (green) according to Bouma [29]. 
The statistical analysis was performed with SPSS (IBM Corp., Armonk, NY, USA). After the descriptive analysis, an unpaired t-test was used for comparisons between the affected and the unaffected hip. To analyze the predictive impact of the postoperative slip angle and the posterior epiphyseal tilt on the alpha angle at the last time of follow-up, a linear regression was performed. The (Pearson) $r$ describes the correlation between both values, which was categorized according to Cohen: $0-0.3$ small; $0.3-0.8$ medium; $>0.8$ strong correlation [30].

\section{Results}

From the 95 remaining cases, 91 children (97.8\%; 41 right side / 50 left side) sustain an unilateral and $2(2.2 \%)$ showed bilateral SCFE at time of diagnosis. The total group included 46 boys $(49.5 \%)$ and 47 girls $(50.5 \%)$ with a mean age of 12.8 years $( \pm 2.2 ; 8.9-16.9)$ and a mean body mass index (BMI) $26.5 \mathrm{~kg} / \mathrm{m}^{2}( \pm 4.2 ; 20.4-33.3)$.

The direct postoperative anatomy of the hip socket on the affected side was $29.6^{\circ}$ $( \pm 6.8 ; 12.1-47.8)$ for the LCEA and $8.7^{\circ}( \pm 4.0 ; 1.2-20.0)$ for the acetabular angle. 37 patients $(38.9 \%)$ presented dysplastic values for at least the LCEA, the acetabular angle or both. Further, radiological signs of a hip retroversion were in 21 cases $(22.1 \%)$ a positive crossover and in 16 cases $(16.8 \%)$ a present PRISS. On the unaffected side, 18 patients $(18.9 \%)$ showed a hip dysplasia with an overall LCEA of $30.0^{\circ}( \pm 6.4 ; 17.0-46.8)$ and a mean acetabular angle of $7.4( \pm 3.8 ; 0.5-22.4)$. The mean radiological follow-up of the 95 cases was 4.3 years $( \pm 1.9 ; 2.0-11.2)$, resulting in a mean age of approximately 17.0 years $( \pm 2.6 ; 11.1-26.5)$. Although the hip socket was not treated, the acetabular anatomy was measured at the last time of the radiological follow-up to observe the further possible changes of the coverage. According to that, 33 patients (34.7\%) had at least one dysplastic socket angle on the affected side with an overall LCEA at the last examination of $27.6^{\circ}( \pm 7.9 ; 8.3-44.0)$ and an acetabular angle of $8.0^{\circ}( \pm 4.4 ; 0.1-20.3)$. From these patients, $21(63.6 \%)$ showed already direct postoperatively dysplastic values. In spite of the small reduction of the acetabular values, the presence of a crossover sign increased to 53 cases (55.8\%) and to 44 cases (46.3\%) with a PRISS. 15 patients (15.8\%) showed a hip dysplasia on the unaffected side at the last time of follow-up, two less than directly after surgery. The socket anatomy was on average with a LCEA of $30.7^{\circ}( \pm 8.7 ; 13.2-49.9)$ and an acetabular angle of $6.5^{\circ}( \pm 4.0 ; 0.4-19.7)$. The mean Southwick angle after surgery was $32.8^{\circ}( \pm 16.0 ; 2.3-76.1): 43(45.3 \%)$ cases in a mild $\left(0-30^{\circ}\right)$ and $36(37.9 \%)$ in a moderate $\left(30-50^{\circ}\right)$ and $16(16.8 \%)$ in a severe $\left(>50^{\circ}\right)$ displaced position, whereas posterior epiphyseal tilt was $18.0^{\circ}( \pm 12.0 ; 1.0-49.6)$. At the last time of the radiological follow-up, the alpha angle was in 46 cases $(48.4 \%)>60^{\circ}$, representing a FAI type cam. In the 93 cases with a unilateral SCFE, the alpha angle of the unaffected side was about $14.4^{\circ}$ lower $\left(50.0 \pm 10.1\right.$ vs. $\left.64.4 \pm 17.7^{\circ}\right)$ compared to the diseased hip $(p=0.001)$.

The correlation between the direct postoperative Southwick angle and the alpha angle at the last time of follow-up was low ( $r=0.03$; Figure 3$)$. Due to the missing correlation, no further observations or statistics were performed.

In contrast to that, the regression between the posterior epiphyseal tilt and the alpha angle of the last radiograph indicated that from a posterior epiphyseal tilt above $16.8^{\circ}$, the estimated alpha angle over time was greater than $60^{\circ}$. The correlation was statistically significant $(p=0.017)$. Per $1^{\circ}$ of the postoperative posterior epiphyseal tilt, the alpha angle increased by $6.18^{\circ}$ in the last radiological examination (Figure 4 ). With a $r=0.27$, a small correlation according to Cohen is present. 


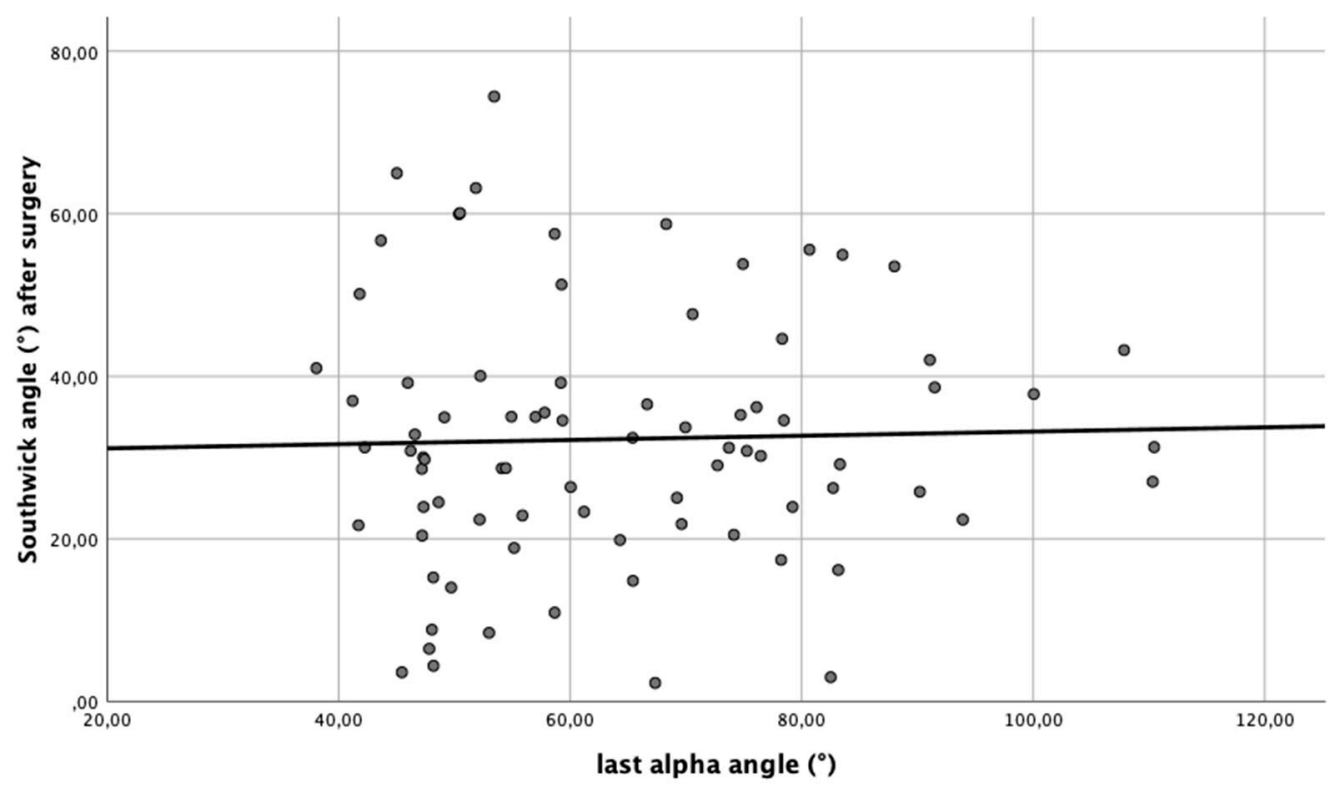

Figure 3. The linear regression between the postoperative absolute Southwick angle and the latest alpha angle showed no significant correlation.

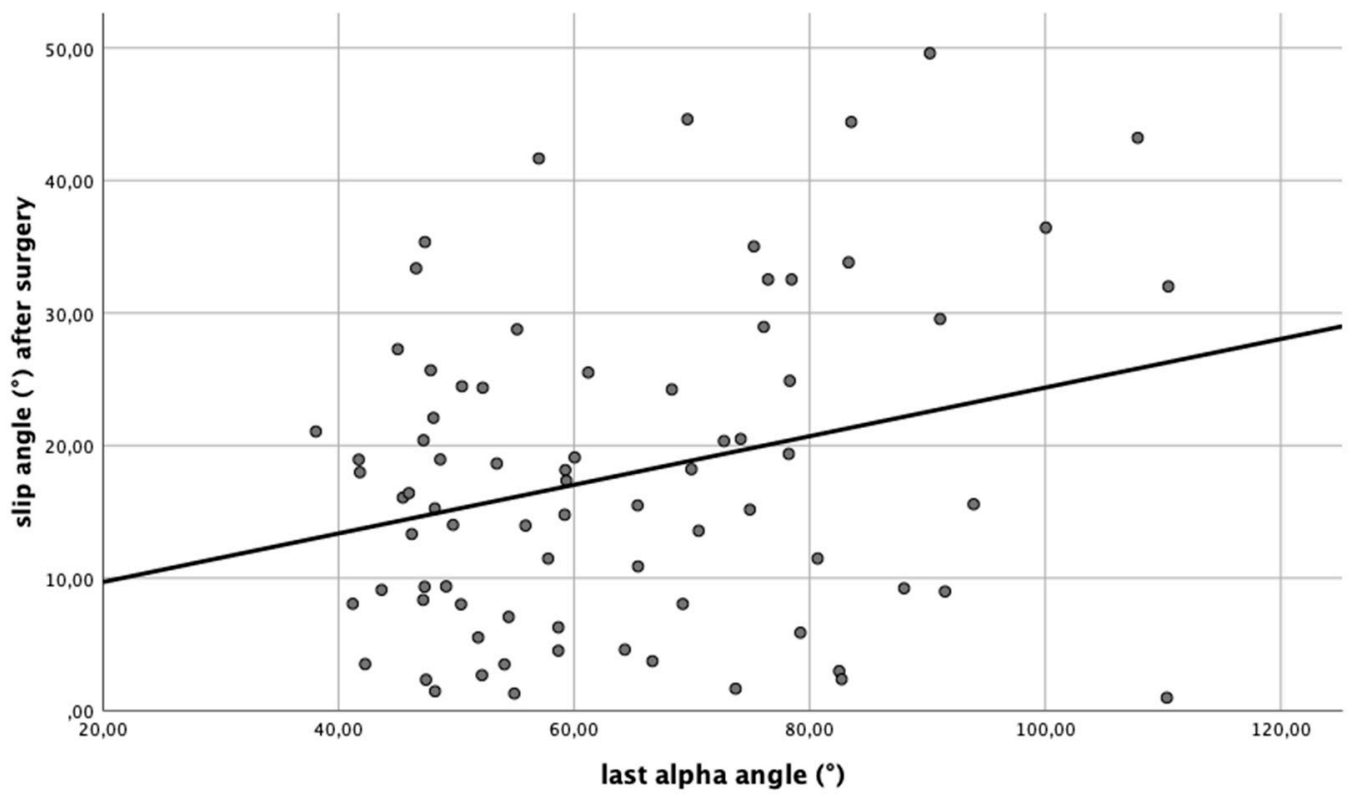

Figure 4. Linear regression $y=6.0+0.18 x$ between the epiphyseal tilt (slip angle) immediately after surgery and the alpha angle at the last time of radiological follow-up. The cut-off value for the postoperative epiphyseal tilt, which was associated with a later cam-deformity occurrence $(x=60)$, was $16.8^{\circ}$.

At the time of surgery, 8 patients $(8.4 \%)$ showed a hip dysplasia on the affected side determined by a LCEA below $20^{\circ}$, whereas 37 patients $(38.9 \%)$ had an acetabular index above $10^{\circ}$, including 6 patients $(6.3 \%)$ with both characteristics. Compared to the unaffected side, the hip joint with the SCFE condition showed a significantly decreased coverage for both parameters (Table 1). However, a statistically significant correlation between the severity of the SCFE and the presence of dysplastic socket angles was not observed $(p>0.05)$. 
Table 1. 41 patients ( $43.2 \%$ ) from the total group ( $n=93$ with unilateral SCFE) had a dysplastic socket anatomy on the affected side with at least one of the following criteria: LCEA $<20.0^{\circ}$, acetabular angle $>10.0^{\circ}$. At the last time of follow-up, the affected side had a decreased coverage compared to the unaffected hip. However, the mean values of both sides were in a physiological range and the clinical relevance might be limited with differences between $1.5^{\circ}$ (acetabular angle)-3.1 ${ }^{\circ}$ (LCEA).

\begin{tabular}{cccc}
\hline & Affected Side & Unaffected Side & $p$ \\
\hline LCEA & $27.6 \pm 7.9$ & $30.7 \pm 8.7$ & 0.001 \\
Acetabular angle & $8.0 \pm 4.4$ & $6.5 \pm 4.0$ & 0.001 \\
\hline
\end{tabular}

\section{Discussion}

During childhood, the SCFE is one of the most prevalent hip disorders, and due to the occurrence in the immature skeleton, the complications in the joint function might extend to further life stages. In spite of an adequate reconstruction, an incongruence of the femoral head neck junction remained in many patients [7]. Experience of pain and limitations in range of movement (ROM) caused by joint impingement, might provide an indication in performing preserving arthroscopies or open procedures. However, it is estimated that the rate of THA after SCFE is about $22.0-45.0 \%$ in middle age [31,32]. Thus, the current study analyzed the rate of hip deformities following a SCFE and predictive factors detecting patients with a high risk for the development of a FAI over time. Further, regarding the coverage the evidence in the international literature is limited and not consistent as ranging from associations with dysplastic and deep sockets [20,21].

First of all, the cohort include common findings regarding the age and BMI. According to this, the mean age was 12.8 years and in range with other population-based results (11.7-13.0) [5]. Further, the mean BMI was $26.5 \mathrm{~kg} / \mathrm{m}^{2}$ and represents under recognition of the mean age a percentile value $>95.0 \%$, which also was observed in other studies $[4,33]$. However, the focus of this retrospective study was the anatomy of the hip socket and the femoral head-neck junction over time after SCFE to determine the frequency of a FAI type cam and a trend to a more retroverted and dysplastic socket shape compared to the unaffected hip joint. The radiographs of the last examination presented an elevated alpha angle $>60^{\circ}$ in $48.4 \%$ of the cases and compared to the unaffected side, the alpha angle was about $14.4^{\circ}$ higher at the joint side sustaining a SCFE $(p<0.001)$. In addition, the patients with an increased alpha angle $\left(>60^{\circ}\right)$ at the last follow-up showed a significant higher perioperative posterior epiphyseal tilt $(15.1 \pm 9.8$ vs. $20.7 \pm 13.8 ;(p<0.01))$. The determined postoperative cut-off value for the reconstructed epiphyseal tilt resulting in a radiological appearance of a FAI type cam (alpha angle $>60^{\circ}$ ) was $16.8^{\circ}$. Although the correlation between both values was statistically significant $(p<0.05)$, the predictable amount was limited with $r=0.27$. However, the postoperative Southwick angle showed no correlation to the latest alpha angle and as such did not present a predictive factor for the occurrence of a FAI type cam over time. Similar results were found by Dodds et al. [34]. The authors analyzed predictive factors for a cam deformity after SCFE in 46 patients. The perioperative slip angle at $r=0.17$ showed a poor correlation to the follow-up alpha angle, so that the authors recommended to monitor all SCFE patients into adulthood for an impingement [34]. Another study also demonstrated a non-significant trend that preoperative slip angles $>35^{\circ}$ were associated with a later onset of an impingement of the hip [35]. Furthermore, the a.p. alpha angle was found as predictive factor for a poor clinical (HHS $<85$ points) as well as radiological follow-up result by Terjesen et al. [36]. In analogy with that, a dysplastic socket anatomy was found in $8.4 \%$ with a LCEA $<20^{\circ}$ and in $38.9 \%$ with an acetabular angle $>10^{\circ}$. Furthermore, the affected hip had a decreased coverage (LCEA/acetabular angle: $27.6 \pm 7.9 / 8.0 \pm 4.4)$ compared to the healthy side (LCEA/acetabular angle: $30.7 \pm 8.7 / 6.5 \pm 4.0)(p<0.001)$. In spite of statistical significance, the clinical relevance might be low, especially because both mean values represent sufficient coverage. The differences in the determined rates of a dysplastic hip anatomy in dependence of the chosen angle, LCEA or acetabular angle, might be explained by the way 
of the measurement. For the determination of the LCEA, the center of the femoral head is required, but the displacement in case of SCFE may lead to a deformed and noncircular shaped femoral head, resulting in an inaccuracy for the determination of the femoral head center while LCEA measurement. Another explanation might be the chosen cut-off values. Defining a dysplastic anatomy with LCEA $<25.0^{\circ}$ and an acetabular angle $>12.0^{\circ}$ might has adjusted the values. However, Maranho et al. also observed in their longitudinal study of 108 patients a tendency to a decreased femoral head coverage of SCFE affected hips [20]. It is supposed, that the epiphyseal displacement might influence the physiological growth of the acetabular socket. According to this, the remodeling after the slip might lead to a relative overgrowth of the femoral head leading to dysplastic conditions or in presence of a FAI the bony might impair the ossification of the acetabular rim [37,38]. Otherwise, some studies observed overcovered anatomies and deep sockets in patients with SCFE [39,40]. In congruence with that, in the time period directly after surgery and to the last radiological follow-up an increase of signs for a retroverted acetabulum was observed. According to that, the among of positive crossover signs raised from $22.1 \%$ to $55.8 \%$ resp. for a PRISS from $16.8 \%$ to $46.3 \%$. In spite of a standardized supine positioning in our institute, the pelvic tilt was not evaluated with the sacrococcygeal-symphysis distance, which might have influenced these results. However, the association between hip pathologies and the presence of an acetabular retroversion was observed. In comparison to the physiological retroversion prevalence of approximately $6 \%$, Bauer et al. found at least one sign (crossover or PRISS) in 79-82\% bilateral resp. unilateral involved SCFE hips [41,42]. These observations were not constantly proofed by other studies [43,44]. The presented results with follow-up examinations showed a hint for a development to an acetabular retroversion in comparison to the direct postoperative results and to the uninvolved side in unilateral cases. However, the association between an acetabular retroversion and a SCFE needs further studies to be proofed.

The study has some limitations. The first aspect was the limited radiological follow-up about 4.3 years $( \pm 1.9 ; 2.0-11.2)$. As a result, deviations of the physiological hip anatomy developing later in the patient's life might not be detected in this study (information bias). This could explain the difference in the rates of detected FAI type cam over the time, $48.4 \%$ in the current work, compared to $91.0 \%$ in candidates for THA [10]. However, the mean age at time of the last radiological follow-up was approximately 17.0 years meaning that the majority of the cohort were followed-up after skeleton maturity. In addition, for young patients with a constant level of their known symptoms after SCFE, frequent radiological follow-up should be carefully discussed regarding radioprotection. Thus, there might be a lack of radiographs to show increasing disabilities between the ages of 20-35 years. Lack of radiation might also explain the usage of conventional radiographs in the current study, although with SCFE representing a three-dimensional slip, a more precise analysis could be performed in CT. However, the indication for a CT in young patients should stay an exception and not be routinely performed. This work analyzed the radiological presence of a bone thickening at the head-neck junction without information about the clinical symptoms or functional limitations of the observed patients. Another limitation was the observational study design resulting in associated biases. According to this the current study has not a comparative character due to a missing patient's group with physiological hip conditions (selection bias) $[45,46]$. However, in the current study the unaffected side of patients sustained from a unilateral SCFE was analyzed and worked as comparative dataset. Another aspect of observational studies is the confounding $[45,46]$. While the association between a SCFE and a development of a FAI type cam over time was proofed in this and previously in other studies, the associated socket morphology is currently discussed in literature and included hints for deep as well as insufficient, dysplastic covering hips $[20,39,40]$. These inconsistent observations might be caused by a confounding factor. 


\section{Conclusions}

The postoperative posterior epiphyseal tilt represented a limited predictive factor to determine the alpha angle over time in patients sustaining a SCFE. However, the cutoff value of the epiphyseal tilt for a later occurrence of a FAI type cam was about $16.8^{\circ}$, indicating a small range of acceptable deviations from the anatomical position for SCFE reconstruction. Because there are no clear predictive factors for the occurrence of an FAI, all patients sustained from SCFE should be followed-up at least once after skeleton maturity.

Author Contributions: N.W.: statistical analysis, manuscript preparation; G.H.: performed measurements, manuscript preparation; A.D.: manuscript review; S.B.: study design, manuscript review; T.F.: study design, control measurements, manuscript review; H.W.: study design, manuscript review, project Administration. All authors have read and agreed to the published version of the manuscript.

Funding: This research received no external funding.

Institutional Review Board Statement: IRB approved by the local ethic committee (No. 8779, Hanover Medical School, 28 November 2019).

Informed Consent Statement: Informed consent was obtained from all subjects involved in the study.

Data Availability Statement: The data presented in this study are available on request from the corresponding author. The data are not publicly available due to privacy protection.

Conflicts of Interest: The authors declare no conflict of interest.

\section{References}

1. Loder, R.T.; Skopelja, E.N. The epidemiology and demographics of slipped capital femoral epiphysis. ISRN Orthop. 2011, 2011, 486512. [CrossRef]

2. Garcia-Mata, S.; Hidalgo-Ovejero, A. Valgus slipped capital femoral epiphysis. Iowa Orthop. J. 2010, 30, $191-194$.

3. Witbreuk, M.; van Kemenade, F.J.; van der Sluijs, J.A.; Jansma, E.P.; Rotteveel, J.; van Royen, B.J. Slipped capital femoral epiphysis and its association with endocrine, metabolic and chronic diseases: A systematic review of the literature. J. Child. Orthop. 2013, 7, 213-223. [CrossRef] [PubMed]

4. Manoff, E.M.; Banffy, M.B.; Winell, J.J. Relationship between Body Mass Index and slipped capital femoral epiphysis. J. Pediatr. Orthop. 2005, 25, 744-746. [CrossRef]

5. Herngren, B.; Stenmarker, M.; Vavruch, L.; Hagglund, G. Slipped capital femoral epiphysis: A population-based study. BMC Musculoskelet Disord. 2017, 18, 304. [CrossRef]

6. Novais, E.N.; Millis, M.B. Slipped capital femoral epiphysis: Prevalence, pathogenesis, and natural history. Clin. Orthop. Relat. Res. 2012, 470, 3432-3438. [CrossRef] [PubMed]

7. Aprato, A.; Conti, A.; Bertolo, F.; Masse, A. Slipped capital femoral epiphysis: Current management strategies. Orthop. Res. Rev. 2019, 11, 47-54. [CrossRef]

8. Ganz, R.; Parvizi, J.; Beck, M.; Leunig, M.; Notzli, H.; Siebenrock, K.A. Femoroacetabular impingement: A cause for osteoarthritis of the hip. Clin. Orthop. Relat. Res. 2003, 417, 112-120. [CrossRef]

9. Clohisy, J.C.; Baca, G.; Beaule, P.E.; Kim, Y.J.; Larson, C.M.; Millis, M.B.; Podeszwa, D.A.; Schoenecker, P.L.; Sierra, R.J.; Sink, E.L.; et al. Descriptive epidemiology of femoroacetabular impingement: A North American cohort of patients undergoing surgery. Am. J. Sports Med. 2013, 41, 1348-1356. [CrossRef] [PubMed]

10. Murgier, J.; Espie, A.; Bayle-Iniguez, X.; Cavaignac, E.; Chiron, P. Frequency of radiographic signs of slipped capital femoral epiphysiolysis sequelae in hip arthroplasty candidates for coxarthrosis. Orthop. Traumatol. Surg. Res. 2013, 99, 791-797. [CrossRef]

11. Samelis, P.V.; Papagrigorakis, E.; Konstantinou, A.L.; Lalos, H.; Koulouvaris, P. Factors Affecting Outcomes of Slipped Capital Femoral Epiphysis. Cureus 2020, 12, e6883. [CrossRef] [PubMed]

12. Akiyama, M.; Nakashima, Y.; Kitano, T.; Nakamura, T.; Takamura, K.; Kohno, Y.; Yamamoto, T.; Motomura, G.; Ohishi, M.; Hamai, S.; et al. Remodelling of femoral head-neck junction in slipped capital femoral epiphysis: A multicentre study. Int. Orthop. 2013, 37, 2331-2336. [CrossRef]

13. Notzli, H.P.; Wyss, T.F.; Stoecklin, C.H.; Schmid, M.R.; Treiber, K.; Hodler, J. The contour of the femoral head-neck junction as a predictor for the risk of anterior impingement. J. Bone Jt. Surg. Br. 2002, 84, 556-560. [CrossRef]

14. Fraitzl, C.R.; Kafer, W.; Nelitz, M.; Reichel, H. Radiological evidence of femoroacetabular impingement in mild slipped capital femoral epiphysis: A mean follow-up of 14.4 years after pinning in situ. J. Bone Jt. Surg. Br. 2007, 89, 1592-1596. [CrossRef] [PubMed]

15. Grace, T.; Samaan, M.A.; Souza, R.B.; Link, T.M.; Majumdar, S.; Zhang, A.L. Correlation of Patient Symptoms With Labral and Articular Cartilage Damage in Femoroacetabular Impingement. Orthop. J. Sports Med. 2018, 6, 2325967118778785. [CrossRef] 
16. Lund, B.; Nielsen, T.G.; Lind, M. Cartilage status in FAI patients-Results from the Danish Hip Arthroscopy Registry (DHAR). SICOT J. 2017, 3, 44. [CrossRef] [PubMed]

17. Tang, H.C.; Chen, I.J.; Sadakah, M.; Wirries, N.; Dienst, M. Preoperative Alpha Angles Can Predict Severity of Acetabular Rim Chondral Damage in Symptomatic Cam-Type Femoroacetabular Impingement: A Prospective Observatory Study. Arthroscopy 2021. [CrossRef] [PubMed]

18. Beck, M.; Kalhor, M.; Leunig, M.; Ganz, R. Hip morphology influences the pattern of damage to the acetabular cartilage: Femoroacetabular impingement as a cause of early osteoarthritis of the hip. J. Bone Jt. Surg. Br. 2005, 87, 1012-1018. [CrossRef]

19. Pun, S.; Kumar, D.; Lane, N.E. Femoroacetabular impingement. Arthritis. Rheumatol. 2015, 67, 17-27. [CrossRef] [PubMed]

20. Maranho, D.A.; Davila-Parrilla, A.; Miller, P.E.; Kim, Y.J.; Novais, E.N.; Millis, M.B. Acetabular morphology in slipped capital femoral epiphysis: Comparison at treatment onset and skeletal maturity. J. Child Orthop. 2018, 12, 444-453. [CrossRef]

21. Podeszwa, D.A.; Gurd, D.; Riccio, A.; De La Rocha, A.; Sucato, D.J. Increased acetabular depth may influence physeal stability in slipped capital femoral epiphysis. Clin. Orthop. Relat. Res. 2013, 471, 2151-2155. [CrossRef]

22. Hanson, J.A.; Kapron, A.L.; Swenson, K.M.; Maak, T.G.; Peters, C.L.; Aoki, S.K. Discrepancies in measuring acetabular coverage: Revisiting the anterior and lateral center edge angles. J. Hip Preserv. Surg. 2015, 2, 280-286. [CrossRef]

23. Tonnis, D.; Heinecke, A. Acetabular and femoral anteversion: Relationship with osteoarthritis of the hip. J. Bone Jt. Surg. Am. 1999, 81, 1747-1770. [CrossRef] [PubMed]

24. Jones, C.E.; Cooper, A.P.; Doucette, J.; Buchan, L.L.; Wilson, D.R.; Mulpuri, K.; d'Entremont, A.G. Southwick angle measurements and SCFE slip severity classifications are affected by frog-lateral positioning. Skeletal Radiol. 2018, 47, 79-84. [CrossRef] [PubMed]

25. Gautier, E.; Passaplan, C.; Gautier, L. Epiphyseal Angulation and Related Spatial Orientation in Slipped Capital Femoral Epiphysis: Theoretical Model and Biomechanical Explanation of Varus and Valgus Slip. JBJS Open Access 2020, 5, e20.00099. [CrossRef]

26. Novais, E.N.; Kienle, K.P.; Miller, P.E.; Bowen, G.; Kim, Y.J.; Bixby, S.D. Age- and gender-specific variations of the epiphyseal tilt and epiphyseal angle in adolescents without hip pathology. J. Child. Orthop. 2018, 12, 152-159. [CrossRef]

27. Cohen, M.S.; Gelberman, R.H.; Griffin, P.P.; Kasser, J.R.; Emans, J.B.; Millis, M.B. Slipped capital femoral epiphysis: Assessment of epiphyseal displacement and angulation. J. Pediatr. Orthop. 1986, 6, 259-264. [CrossRef]

28. Werner, C.M.; Copeland, C.E.; Ruckstuhl, T.; Stromberg, J.; Turen, C.H.; Kalberer, F.; Zingg, P.O. Radiographic markers of acetabular retroversion: Correlation of the cross-over sign, ischial spine sign and posterior wall sign. Acta Orthop. Belg. 2010, 76, 166-173.

29. Bouma, H.; Slot, N.J.; Toogood, P.; Pollard, T.; van Kampen, P.; Hogervorst, T. Where is the neck? Alpha angle measurement revisited. Acta Orthop. 2014, 85, 147-151. [CrossRef]

30. Lakens, D. Calculating and reporting effect sizes to facilitate cumulative science: A practical primer for t-tests and ANOVAs. Front. Psychol. 2013, 4, 863. [CrossRef]

31. Nelms, N.J.; Lewallen, L.W.; McIntosh, A.L.; Sierra, R.J. Total hip arthroplasty in the young: Special emphasis on post-SCFE patients. J. Pediatr. Orthop. 2013, 33 (Suppl. 1), S137-S142. [CrossRef]

32. Aronson, J. Osteoarthritis of the young adult hip: Etiology and treatment. Instr. Course Lect. 1986, 35, 119-128. [PubMed]

33. Aversano, M.W.; Moazzaz, P.; Scaduto, A.A.; Otsuka, N.Y. Association between body mass index-for-age and slipped capital femoral epiphysis: The long-term risk for subsequent slip in patients followed until physeal closure. J. Child. Orthop. 2016, 10, 209-213. [CrossRef] [PubMed]

34. Dodds, M.K.; McCormack, D.; Mulhall, K.J. Femoroacetabular impingement after slipped capital femoral epiphysis: Does slip severity predict clinical symptoms? J. Pediatr. Orthop. 2009, 29, 535-539. [CrossRef]

35. Nectoux, E.; Decaudain, J.; Accadbled, F.; Hamel, A.; Bonin, N.; Gicquel, P.; French society of Orthopedic, T.S. Evolution of slipped capital femoral epiphysis after in situ screw fixation at a mean 11 years' follow-up: A 222 case series. Orthop. Traumatol. Surg. Res. 2015, 101, 51-54. [CrossRef] [PubMed]

36. Terjesen, T.; Wensaas, A. Prognostic factors for long-term outcome of chronic slipped capital femoral epiphysis treated with fixation in situ. J. Child. Orthop. 2017, 11, 114-119. [CrossRef] [PubMed]

37. Hesper, T.; Bixby, S.D.; Kim, Y.J.; Yen, Y.M.; Bowen, G.; Miller, P.; Millis, M.B.; Novais, E.N. Acetabular Retroversion, but Not Increased Acetabular Depth or Coverage, in Slipped Capital Femoral Epiphysis: A Matched-Cohort Study. J. Bone Jt. Surg. Am. 2017, 99, 1022-1029. [CrossRef]

38. Siebenrock, K.A.; Anwander, H.; Zurmuhle, C.A.; Tannast, M.; Slongo, T.; Steppacher, S.D. Head reduction osteotomy with additional containment surgery improves sphericity and containment and reduces pain in Legg-Calve-Perthes disease. Clin. Orthop. Relat. Res. 2015, 473, 1274-1283. [CrossRef]

39. Monazzam, S.; Krishnamoorthy, V.; Bittersohl, B.; Bomar, J.D.; Hosalkar, H.S. Is the acetabulum retroverted in slipped capital femoral epiphysis? Clin. Orthop. Relat. Res. 2013, 471, 2145-2150. [CrossRef]

40. Sankar, W.N.; Brighton, B.K.; Kim, Y.J.; Millis, M.B. Acetabular morphology in slipped capital femoral epiphysis. J. Pediatr. Orthop. 2011, 31, 254-258. [CrossRef] [PubMed]

41. Bauer, J.P.; Roy, D.R.; Thomas, S.S. Acetabular retroversion in post slipped capital femoral epiphysis deformity. J. Child. Orthop. 2013, 7, 91-94. [CrossRef] [PubMed]

42. Fujii, M.; Nakashima, Y.; Yamamoto, T.; Mawatari, T.; Motomura, G.; Matsushita, A.; Matsuda, S.; Jingushi, S.; Iwamoto, Y. Acetabular retroversion in developmental dysplasia of the hip. J. Bone Jt. Surg. Am. 2010, 92, 895-903. [CrossRef] 
43. Kordelle, J.; Richolt, J.A.; Millis, M.; Jolesz, F.A.; Kikinis, R. Development of the acetabulum in patients with slipped capital femoral epiphysis: A three-dimensional analysis based on computed tomography. J. Pediatr. Orthop. 2001, 21, 174-178. [CrossRef]

44. Stanitski, C.L.; Woo, R.; Stanitski, D.F. Acetabular version in slipped capital femoral epiphysis: A prospective study. J. Pediatr. Orthop. B 1996, 5, 77-79. [CrossRef] [PubMed]

45. Grimes, D.A.; Schulz, K.F. Bias and causal associations in observational research. Lancet 2002, 359, 248-252. [CrossRef]

46. Hammer, G.P.; du Prel, J.B.; Blettner, M. Avoiding bias in observational studies: Part 8 in a series of articles on evaluation of scientific publications. Dtsch. Arztebl. Int. 2009, 106, 664-668. [CrossRef] 